\title{
Comment on: Risk Factors for Survival After Lung Metastasectomy for Colorectal Cancer Patients
}

\author{
Kazuhiro Watanabe, $\mathrm{MD}, \mathrm{PhD}^{1,2}$, Samer Salah, $\mathrm{MD}, \mathrm{PhD}^{3}$, and Norio Saito, $\mathrm{MD}, \mathrm{PhD}^{1}$ \\ ${ }^{1}$ Surgical Oncology, National Cancer Center Hospital East, Kashiwa, Chiba, Japan; ${ }^{2}$ Surgery, Tohoku University Graduate \\ School of Medicine, Sendai, Miyagi, Japan; ${ }^{3}$ Medical Oncology, King Hussein Cancer Center, Amman, Jordan
}

\section{TO THE EDITORS:}

With a great interest, we have read the article "Risk Factors for Survival After Lung Metastasectomy in Colorectal Cancer Patients: A Systematic Review and Meta-Analysis" by Dr. Gonzalez and his colleagues. ${ }^{1}$

We appreciate the authors' reference to our recent papers. ${ }^{2,3}$ However, an issue in their article is not referenced correctly to my paper.

In Table 1, the authors report that the prognostic factor after pulmonary metasectomy from colorectal cancer was "normal CEA" and "no lymph node" in our study. ${ }^{1,2}$ This is not correct. "Normal CEA" and "no lymphatic invasion by pulmonary tumor" were the prognostic factors in our paper. $^{2}$ No lymph node was not a significant prognostic factor because only a few patients had hilar or mediastinal (thoracic) lymph node involvement in our study. Patients with thoracic lymph node involvement were excluded from surgical indication and thoracic lymph node sampling or dissection was not routinely performed at my institution.

Except for this minor issue, we agree with the conclusion of the article. The authors performed meta-analysis and showed that the prognostic factors after pulmonary metasectomy from colorectal cancer were disease-free interval (DFI), carcinoembryonic antigen (CEA), number of lung metastases, and thoracic lymph node involvement. ${ }^{1}$ Our recent international multicenter retrospective study also showed that DFI, CEA, and number of lung metastases were the prognostic factors. ${ }^{3}$

\section{(C) Society of Surgical Oncology 2017}

First Received: 20 October 2017;

Published Online: 30 October 2017

K. Watanabe, MD, PhD

e-mail: k-wata@med.tohoku.ac.jp
The authors reported that our study did not consider thoracic lymph node involvement as a potential determinant of outcome. ${ }^{1}$ However, this was not a very accurate description. Our study showed that thoracic lymph node involvement is a candidate for a prognostic factor because the univariate analysis showed that thoracic lymph node involvement was a significant prognostic factor. ${ }^{3}$ In our study, thoracic lymph node involvement was excluded from the multivariate analysis to avoid bias because the number of patients who underwent thoracic lymph node sampling or dissection was low. Therefore, we agree with the conclusion of the article.

We hope the data from these large-scale studies will facilitate the establishment of novel algorithms for predicting prognosis after resection of pulmonary metastases from colorectal cancer, which may lead to the appropriate therapeutic strategies for pulmonary metastases from colorectal cancer.

\section{REFERENCES}

1. Gonzalez M, Poncet A, Combescure C, Robert J, Ris HB, Gervaz P. Risk factors for survival after lung metastasectomy in colorectal cancer patients: a systematic review and meta-analysis. Ann Surg Oncol. 2012;20(6):1955-61.

2. Watanabe K, Nagai K, Kobayashi A, Sugito M, Saito N. Factors influencing survival after complete resection of pulmonary metastases from colorectal cancer. Br J Surg. 2009;96:1058-65.

3. Salah S, Watanabe K, Welter S, et al. Colorectal cancer pulmonary oligometastases: pooled analysis and construction of a clinical lung metastasectomy prognostic model. Ann Oncol. 2012;23:2649-55. \section{,}

